\title{
CofinanCIAMENTO ESTATAL NO SUS - RE 855.178 ED/SE
}

\section{State Cofinancing In the United Health SYSTeM - $R E 855,178 E D / S E$}

\section{JoÃo Victor TAVARES GaliL}

Mestre em Direito Administrativo pela Pontificia Universidade Católica de São Paulo. Advogado. ORCID: [https://orcid.org/0000-0002-3090-206X].

jvtgdireito@gmail.com

Recebido em: 08.03.2020 Aprovado em: 15.03 .2020

Áreas do DiReito: Constitucional; Processual

Resumo: 0 presente trabalho analisa, ainda que brevemente, a tese fixada pelo Supremo Tribunal Federal após os embargos de declaração no Recurso Extraordinário 855.178 do Estado de Sergipe, sob o qual se discutiu a obrigatoriedade de um ente estatal superior cofinanciar o tratamento concedido pelo SUS no âmbito de ente estatal de competência mais reduzida.

Palavras-chave: Saúde - Responsabilidade estatal - Medicamentos - Reembolso - Competência comum.

\begin{abstract}
The present work analyzes, albeit briefIy, the thesis established by the Supreme Federal Court after the embargoes of declaration in the Extraordinary Appeal 855,178 of the State of Sergipe, under which the obligation of a superior state entity to co-finance the treatment granted by SUS was discussed. state entity with lesser competence.
\end{abstract}

Kerwords: Health - State responsibility - Medicines - Refund - Common competence.

EmentA: Recurso extraordinário. Constitucional e administrativo. Direito à saúde. Tratamento médico. Responsabilidade solidária dos entes federados. Reafirmação de jurisprudência. Recurso extraordinário desprovido. 0 tratamento médico adequado aos necessitados se insere no rol dos deveres do Estado, sendo responsabilidade solidária dos entes federados, podendo figurar no polo passivo qualquer um deles em conjunto ou isoladamente.

SumÁrio: 1. A tese do Supremo Tribunal Federal após Embargos de Declaração do Recurso Extraordinário 855.178 do Estado de Sergipe. 1.1. Situação fática. 1.2. A análise da Corte. 2. Breves comentários. Referências bibliográficas.

\footnotetext{
GALIL, João Victor Tavares. Cofinanciamento estatal no SUS - RE 855.178 ED/SE. Revista de Direito Administrativo, Infraestrutura, Regulação e Compliance. n. 13. ano 4. p. 345-350. São Paulo: Ed. RT, abr.-jun. 2020.
} 


\section{A tese do Supremo Tribunal Federal após Embargos de Declaração do ReCuRso EXtraordináRIO 855.178 do Estado de SergIPE}

\subsection{Situação fática}

Trata-se o julgado de decisão proferida em Embargos de Declaração apresentados em razão de acordão publicado no dia 16 de março de 2015 referente a Recurso Extraordinário interposto pela União após decisão à qual não se conformou, proferida essa pelo Tribunal Regional Federal da $5^{a}$ Região, sediado em Recife (PE).

O caso teve origem no Estado de Sergipe, ocasião na qual a autora da ação em primeira instância visava o fornecimento da medicação de nome Bosentana (TRACLEEER $62.5 \mathrm{mg} / 125 \mathrm{mg}$ ), indicada a pacientes com hipertensão arterial pulmonar. Deferido o pedido, fora determinada a aquisição da medicação pelo Estado de Sergipe e o cofinanciamento desta pela União Federal, na parcela de $50 \%$ (cinquenta por cento).

O Estado de Sergipe procedeu a entrega do medicamento por meio de sua Secretaria de Saúde até a vinda da condição resolutiva configurada no falecimento da autora, cerca de dois meses após a determinação judicial. Ainda assim, permaneceu o inconformismo da União quanto à ordem de ressarcimento do custeio do medicamento ao Estado da Federação. Em sede de apelação, o Tribunal competente entendeu pela solidariedade constitucional do dever de prestar assistência à saúde, compartilhado entre a União, os Estados e os Municípios, inafastável pela distribuição de atribuições entre os entes federativos por normas infraconstitucionais.

\subsection{A análise da Corte}

A questão chegou ao STF sob a alegação da União de violação aos arts. $2^{\circ} \mathrm{e}$ 198, ambos da Constituição Federal. Afirmara, a União, a sua ilegitimidade passiva, sustentada em razão de ser o Sistema Único de Saúde - SUS pautado pelo princípio da descentralização, de modo que a obrigação de fornecer e custear os medicamentos seria de incumbência exclusiva dos órgãos locais.

O Acordão proferido no dia 05 de março de 2015 teve, como relator, o Min. Luiz Fux, que conferiu razão à Corte regional cujo teor, a seu ver, aproximava-se, entre outras, da decisão emitida pelo Min. Gilmar Mendes no julgamento da Suspensão de Segurança 3.355. Nessa oportunidade, ressalta-se, foram identificadas quatro diretrizes constitucionais no tocante à prestação do serviço de saúde: direção administrativa única em cada nível de governo; descentralização

GAull, João Victor Tavares. Cofinanciamento estatal no SUS - RE 855.178 ED/SE. 
político-administrativa; atendimento integral, com preferência para as atividades preventivas; e participação da comunidade. Essas diretrizes, balizadas pelo dever comum dos entes políticos imposto pelo art. 196, como pela competência sobre a saúde atribuída a todos pelo art. 23, II, da Constituição da República, revigoradas ainda pela Emenda Constitucional 20/2000, a qual, por sua vez, estabelece redação do art. $198, \S 1^{\circ}$, responsável por afirmar o cofinanciamento do SUS pelos entes federativos com recursos do orçamento da seguridade social, serviram para fundamentar a decisão em prol da corresponsabilidade dos entes, revigorando o que havia sido, até ali, decidido. Vale ressaltar que o Ministro destacou o fato de o art. 196 ser claro ao afirmar a responsabilidade estatal para o acesso igualitário e universal de todos. Alinhou-se, conforme o relator, a julgados anteriores da Casa: AI 822.882-AgR, Rel. Min. Roberto Barroso, Primeira Turma, DJe 06.08.2014; ARE 803.274-AgR, Rel. Min. Teori Zavascki, Segunda Turma, DJe 28.05.2014; ARE 738.729-AgR, Rel. Min. Rosa Weber, Primeira Turma, DJe 15.08.2013; ARE 744.170-AgR, Rel. Min. Marco Aurélio, Primeira Turma, DJe 03.02.2014; RE 716.777-AgR, Rel. Min. Celso de Mello, Segunda Turma, DJe 16.05.2013; RE 586.995-AgR, Rel. Min. Cármen Lúcia, Primeira Turma, DJ 16.08.2011; RE 607.381-AgR, Rel. Min. Luiz Fux, Primeira Turma, DJ 17.06.2011; RE 756.149-AgR, Rel. Min. Dias Toffol; Primeira Turma, DJ 18.02.2014; AI 808.059-AgR, Rel. Min. Ricardo Lewandowski, Primeira Turma, DJe 02.12.2010.

Opostos embargos de declaração no dia 07 de abril de 2015, rejeitados pelo Min. Luiz Fux, os autos seguiram para vista do Min. Edson Fachin, cujo voto dirigiu a rejeição pela Corte no dia 22 de maio de 2019 e se sobrepôs aos pareceres dos Ministros Dias Toffoli, Alexandre de Moraes, Luiz Fux e Roberto Barroso. Na sequência, foi fixada tese de repercussão geral (Tema 793), que endossou os termos anteriormente apresentados em 2015, de maneira a reconhecer a solidariedade dos entes federativos na prestação dos serviços de saúde, de decorrência da competência comum que se lhes foi atribuída. Segundo entendimento fixado na Corte, ainda, segundo critérios de descentralização e hierarquização, caberia ao magistrado fixar o cumprimento da exigência constitucional com base em regras de repartição de competências, determinado o cofinanciamento, ainda que por forma de reembolso, dos demais entes que não atuarem diretamente em determinado caso decidido.

\section{BREVES COMENTÁRIOS}

Com a manifestação do Supremo Tribunal Federal a respeito do tema 793 de repercussão geral, mais uma vez a Corte dá um passo importante para reconhecer

Gall, João Victor Tavares. Cofinanciamento estatal no SUS - RE 855.178 ED/SE. Revista de Direito Administrativo, Infroestrutura, Regulação e Compliance. n. 13. ano 4. p. 345-350. São Paulo: Ed. RT, abr.-jun. 2020. 
a amplitude especial que a Constituição Federal exige para a prestação dos serviços de saúde, destacando-a, inclusive, no âmbito dos próprios serviços sociais, ou seja, ao lado dos serviços de educação, assistência e previdência sociais, resumidamente. A questão não é de causar espanto, visto que já vinha o Tribunal seguido tal conduta em diversos julgados anteriores, citados na decisão de 2015.

Para além do mérito dos autos que aqui se comentam, compõe afirmar que o STF já vinha se manifestando em prol da especialidade do serviço de saúde, como é o caso do julgado no RE 566.471-RG, Rel. Min. Marco Aurélio, em que se debateu o dever do Estado de fornecer medicamento de alto custo a portador de doença grave que não poderia comprá-lo em razão de situação financeira ou, ainda, no julgado do RE 597.064/RJ, Rel. Min. Gilmar Mendes, pelo qual se determinou o reembolso pelas operadoras de planos de saúde ao Sistema único de Saúde em razão de atendimento a segurados não atendidos na rede privada.

A Constituição Federal, por sua vez, deixa claro a posição diferenciada que a atividade prestacional ocupa no programa do Estado Brasileiro. Diferentemente dos demais, deixa expressa a possibilidade de participação de particulares em caráter suplementar e complementar ao Poder Público, agindo tanto de forma lucrativa quanto não interessada sob princípios de direito privado, embora sob forte regulação estatal, quanto sob parâmetros de direito público. Deixa clara, ainda, a possibilidade de celebração de convênios com entidades sem fins lucrativos, conforme reza seu art. 199, $\S 1^{\circ}$, em única passagem pela qual prevê sobre tais atos bilaterais.

O que se percebe da redação constitucional é que o constituinte foi enfático e desejou reunir esforços de todo o corpo social, estatal ou não, para a disponibilização da saúde ao cidadão, com o cuidado de não deixar vácuos que, por óbvio, impactariam diretamente a vida dos usuários. Essa ideologia é a que justifica a própria existência do SUS.

Extrai-se da Corte que o SUS é pautado pelo princípio da subsidiariedade, o que merece comentários. O princípio da subsidiariedade é um vetor interpretativo originado de ensinamentos sociais da Igreja Católica ${ }^{1}$. Em brevíssi-

1. Sílvio Luís Ferreira da Rocha ensina que a origem histórica do princípio em comento se deu com a doutrina social da Igreja Católica, ilustrada pela Encíclica Rerum Novarum do Papa Leão XIII (1891) e, posteriormente, Encíclica Quadragesimo Anno. Basicamente, afirma que uma entidade superior não deve realizar os interesses da coletividade inferior quando esta for capaz de supri-los de maneira mais eficaz, cabendo ao ente maior atuar nas matérias que não possam ser assumidas - ou que não o possam, de maneira mais adequada -, pelos grupos sociais menores. $\mathrm{O}$ autor ainda observa que houve sua

GaLlL, João Victor Tavares. Cofinanciamento estatal no SUS - RE 855.178 ED/SE .
Revista de Direito Administrativo, Infraestrutura, Regulaçõo e Compliance.

n. 13. ano 4. p. 345-350. São Paulo: Ed. RT, abr.-jun. 2020. 
mos termos, afirma que não deve competir ao ente maior realizar algo que pode ser realizado por entes menores, sob pena de ofender a própria existência e desenvolvimento destes. Esse vetor terminou por influenciar correntes políticas simpatizantes do modelo de Administração Gerencial, relacionado a uma participação direta cada vez menor do Poder Público, que passaria tão somente a regular as atividades privadas, permitindo-lhes maior margem de atuação em razão de um claro afastamento estatal.

Muito embora tal ideologia tenha influenciado política e juridicamente o cenário nacional após os anos 1990, a questão é que o tratamento diferenciado conferido à saúde impede que assim se perceba sua incidência. Não se está a negar que, de certa forma, a União não agirá quando o Município puder fazê-lo, mas tal característica não se confere em inatividade, como se poderia perceber do princípio da subsidiariedade. Eis aí o motivo para se falar em cofinanciamento.

A descentralização praticada no âmbito do SUS tem um dever claro: concretizar o princípio da igualdade ${ }^{2}$. Como se sabe, falar-se em igualdade significa desigualar situações a medida de sua desigualdade. Ora, se a aplicação fosse centralizada e uniforme, o direito fundamental de alguém no interior do Amazonas sofreria flagrante redução, corroborada pelo sistema jurídico, se comparada a um usuário no Vale do Paraíba. Ao contrário do que se pode entender, tal medida tem fins de acesso universal amplo e facilitado, mas não visa reduzir responsabilidades. Apesar de se fundamentar em vetor interpretativo que, ao que aqui se percebe, é incabível, não se pode dizer que a Corte se equivocou na terapêutica.

Um ponto que merece críticas, por outro lado, é o fato de a tese fixada determinar que cabe ao magistrado fixar regras para o cumprimento da política pública.

reafirmação pela Encíclica Mater et Magistra (1961), do Papa João XXIII, e pela Encíclica Centesimo Anno, outorgada pelo Papa João Paulo II, que o reconheceu como princípio regente das relações dos poderes públicos com os cidadãos, as famílias e os corpos intermediários (Terceiro setor. São Paulo: Malheiros Editores, 2006. p. 15-16). Gilberto Bercovici, por sua vez, encontra o princípio positivado pela Carta del Lavoro, editada por Benito Mussolini em 1927, e que sustentou a iniciativa econômica pública na Espanha franquista e no Brasil nas ditaduras de Vargas e na militar (BERCOVICI, Gilberto. Direito econômico do petróleo e dos recursos minerais. São Paulo: Quartier Latin, 2011. p. 268/269). Este encontra apoio na obra de Rafael Valim (VALIM, Rafael. A subvençãono direito administrativo brasileiro. São Paulo: Contracorrente, 2015; V/rodapé n. 48. p. 36).

2. Em sentido semelhante, manifesta-se MARTINS, Ricardo Marcondes. Estudos de direito administrativo neoconstitucional. São Paulo: Malheiros Editores, 2015. p. 115-121. Apesar de o autor se manifestar sobre normas gerais de direito urbanístico, o seu tratamento sobre a igualdade encontra perfeita aplicabilidade ao aqui tratado.

GALLL, João Victor Tavares. Cofinanciamento estatal no SUS - RE 855.178 ED/SE . Revista de Direito Administrativo, Infraestrutura, Regulação e Compliance. n. 13. ano 4. p. 345-350. São Paulo: Ed. RT, abr.-jun. 2020. 
Ora, não cabe ao magistrado exercer discricionariedades, mas impor à Administração aquilo que se lhe dita o Direito. Dessa maneira, deve o juiz esclarecer as exigências do sistema jurídico e ouvir a Administração naquilo que o Direito não lhe confere resposta certa ${ }^{3}$. Não deve realizar ponderações para o caso concreto, competência própria do administrador, mas deve coletar termos do Poder Público com fins a torná-los obrigatórios e evitar, assim, que se desvie do dever de prestar atenção ao cidadão.

\section{REFERÊNCIAS BIBLIOGRÁFICAS}

BERCOVICI, Gilberto. Direito econômico do petróleo e dos recursos minerais. São Paulo: Quartier Latin, 2011.

GALIL, João Victor Tavares. Espaço de negociação no cumprimento da função estatal. Revista Brasileira de Infraestrutura - RBINF, Belo Horizonte, ano 8, p. 143-160, 2019.

MARTINS, Ricardo Marcondes. Estudos de direito administrativo neoconstitucional. São Paulo: Malheiros Editores, 2015.

ROCHA, Sílvio Luis Ferreira. Terceiro setor. São Paulo: Malheiros Editores, 2006.

VALIM, Rafael. A subvenção no direito administrativo brasileiro. São Paulo: Contracorrente, 2015.

\section{Pesouisas do Editorial}

\section{Veja também Doutrinas}

- Ações de saúde contra o poder público: ensaio de um roteiro decisório, de Francisco Glauber Pessoa Alves - RePro 259/333-370 (DTR|2016|22780); e

- A tutela jurisdicional da saúde, de Fabio Caldas de Araújo e Celso Hiroshi locohama RDM2 (DTR|2019|35450).

3. Nesse sentido: GALIL, João Victor Tavares. Espaço de negociação no cumprimento da função estatal. Revista Brasileira de Infraestrutura-RBINF, Belo Horizonte, ano 8, 2019. p. 143-160.

\footnotetext{
GALL, João Victor Tavares. Cofinanciamento estatal no SUS - RE 855.178 ED/SE . Revista de Direito Administrativo, Infraestrutura, Regulação e Compliance. n. 13. ano 4. p. 345-350. São Paulo: Ed. RT, abr.-jun. 2020.
} 